\title{
FRANCISCO ESPÍNOLA, NARRADOR
}

\author{
POR \\ ARTURO SERGIO VISCA \\ Academia Nacional de Letras
}

\section{FISONOMIA DE UN ESCRITOR}

1.1. Cuando en el año 1962, un jurado integrado por 21 miembros, y presidido por el Rector de la Universidad, confirió a Francisco Espínola el Gran Premio Nacional de Literatura, máxima distinción concedida a un escritor en el Uruguay, el premio, en rigor, no hizo más que confirmar el juicio explícitamente formulado por la crítica literaria nacional e implícitamente denotado por los lectores, que agotaban las ediciones del escritor premiado. Según ese juicio, en el que crítica y lectores coincidían, Francisco Espínola era -como efectivamente lo es- una de las figuras señeras de la promoción de escritores que, en el Uruguay, surgieron a la vida literaria en la década de los años veinte. La creación literaria de Francisco Espínola, que nació en San José de Mayo el 4 de octubre de 1901 y murió en Montevideo el 26 de junio de 1973, no es, sin embargo, muy extensa. En vida, publicó dos libros de cuentos, Raza ciega (Montevideo: La Cruz del Sur, 1926) y El rapto (Montevideo: Número, 1950), ${ }^{1}$ un relato para niños, Saltoncito (Montevideo: Impresora Uruguaya S.A., 1932), una novela, Sombras sobre la tierra (Montevideo-Buenos Aires: Ediciones de la Sociedad Amigos del Libro Rioplatense, 1933), una pieza teatral, La fuga en el

\footnotetext{
${ }^{1}$ La versión definitiva, preparada por el autor, de los cuentos de Francisco Espínola, se halla en la edición titulada Cuentos completos (Montevideo: Publicaciones de la Universidad de la República, 1961). Reúne, junto con "Saltoncito", 16 cuentos: los 9 de Raza ciega, los 4 de El rapto y otras cuentos y 3 que hasta entonces no habían sido recogidos en libro. Los textos de esa edición presentan variantes - en algunos muy numerosas-en relación con las ediciones anteriores. Lo mismo ocurre con Sombras sobre la tierra, cuya tercera edición (Montevideo: Centro de Estudiantes de Derecho, 1966), también preparada por el autor, es la definitiva. Tanto en los cuentos como en la novela, las variantes son de muy varia índole, pero abundan, en los dí́logos, las destinadas a corregir las incorrecciones del lenguaje mediante las que se procuraba reproducir el habla del habitante de la campaña uruguaya. El autor conservó solo las imprescindibles para que los personajes no se descaractericen y para que la atmósfera del relato no pierda calor y color local, que, conviene subrayarlo, no es en los textos de Espinola mero costumbrismo.
} 
espejo (Montevideo: Editorial Alba, 1937)² y una meditación sobre lo bello y la recepción estética, Milón o el ser del circo (Montevideo: Impresora Uruguaya, 1954), ${ }^{3}$ escrita en forma de diálogo; póstumamente, se publicaron otros dos libros: una novela, Don Juan, el Zorro (Montevideo: Arca, 1984), ${ }_{4}^{4}$ que, tras una larga gestación, al morir el autor quedó inconclusa, y Veladas del fogón (Montevideo: Arca, 1985), que reúne enero y agosto de 1935, en la Revista para los Hogares Argentinos, suplemento semanal del diario bonaerense Crítica.

1.2. Además de la creación literaria puesta de manifiesto en los libros referenciados, el autor de Raza ciega desenvolvió - como conferencista, crítico teatral, docente y prologuista de libros ajenos - una actividad intelectual que tuvo vasta influencia en la vida cultural del Uruguay. Fueron decisivas para la actualización y revaloración de Eduardo Acevedo Díaz (1851-1921), cronológicamente el primer gran novelista uruguayo, las conferencias pronunciadas en el paraninfo de la Universidad, en el año 1945; fueron memorables sus cursos, dictados en la Facultad de Humanidades y Ciencias de Montevideo, sobre la Ilíada y la Odisea y sobre Composición Literaria; fueron de muy alto nivel, y, al mismo tiempo, de gran penetración popular, sus disertaciones televisivas sobre Cervantes. Su acción docente se prolongaba, fuera del aula, y ante amigos y discípulos, en interminables charlas, a través de las que ejercía, como sin proponérselo, un magisterio que fabulosamente combinaba la originalidad del enfoque, cualquiera fuera el tema tratado, la agudeza intelectual, la campechanía campesina y la gracia de un habla coloquial sabiamente manejada. No menos singularizante de su personalidad fue su estupenda condición de narrador oral ( 0 , en términos rioplatenses, de "narrador de fogón"). Inflexiones de la voz, gestos del rostro, ademanes de las manos, pausas estratégicamente ubicadas en el discurso narrativo, y desde luego, su

${ }^{2}$ Fue estrenada en el Teatro Urquiza, por la Compañía Nacional de Comedia, el 23 de mayo de 1937. La obra, que el autor caracteriza como drama-pantomima, se vale de tres medios expresivos: prosa, verso y danza. Es un original aporte al teatro uruguayo. Su puesta en escena provocó polémicas. La edición referenciada contiene un excelente prólogo de Roberto Ibáñez, que analiza con rigor crítico la obra.

3 También esta obra, editada con un penetrante prólogo de Esther de Cáceres, tuvo derivaciones polémicas. En el semanario montevideano Marcha, en las entregas del 26 de agosto y 2 de septiembre de 1955, se enfrentaron polémicamente Emir Rodríguez Monegal y Eugenio Coseriu. La jerarquía de los polemistas y los argumentos esgrimidos hicieron de la controversia un válido ahondamiento crítico en la obra.

4 De esta novela, el autor hizo conocer, en diversas publicaciones periódicas, algunos capítulos. La más extensa de esas publicaciones fue la realizada por Capitulo Oriental, que historió la literatura uruguaya a lo largo de 38 fascículos, aparecidos semanalmente. Tres capítulos de la novela ("La comisaria", "La pulpería" y "La muerte de los Sargentos y de la Mulita") integraron un volumen que formaba parte de la entrega № 26: Francisco Esptnola/ Vida y obra (Buenos Aires-Montevideo: Centro Editor de América Latina, 1968). 
muy rica inventiva y su destreza de narrador nato, que hacía de cada uno de sus cuentos una pequeña joya mímicoverbal, convirtieron a Espínola, como narrador oral, en una figura casi legendaria. Estos perfiles de su personalidad, y otros no menos singulares, justifican que un crítico haya afirmado que Francisco Espínola - popularmente Paco- era no sólo un escritor sino también una “institución nacional". Fue, sin lugar a dudas, el maestro, casi sin excepción reconocido como tal, de más de una generación de escritores uruguayos. Al respecto, en nota titulada "Los treinta años de Sombras sobre la tierra", publicada en el matutino montevideano El País el 13 de septiembre de 1962, Emir Rodríguez Monegal afirma taxativamente:

Treinta años hace que Sombras sobre la tierra empezó a existir en nuestra literatura. En esos treinta años, Espínola escribió otros relatos, aparecieron libros de muchos valiosos narradores, se formaron (por lo menos) dos generaciones nuevas. Sobre todos ellos pesa de alguna manera la influencia de Espínola. Sin Espínola sería muy difícil entender la evolución de la narrativa uruguaya. Muchos de los que parecen maestros de hoy, incluso aquellos que están más alejados por su temática superficial (como Juan Carlos Onetti) arrancan de Espinola. Pocas veces un autor y un libro han tenido tan larga descendencia.

1.3. El mundo imaginario creado por Espínola, único sector de su obra que será objeto de estudio en el presente ensayo crítico, describe una parábola creadora en la que es perceptible una matizada gama de entonaciones narrativas. El mundo imaginario constituido por los cuentos de Raza ciega difiere del que se hace visible en Sombras sobre la tierra. Yambos muestran diferencias notorias con los cuentos reunidos en El rapto y otros cuentos, que, a su vez, no constituyen un grupo homogéneo. Nuevas diferencias se hacen ostensibles cuando se accede a Saltoncito, Don Juan, el Zorro y los tres cuentos incorporados a la edición de Cuentos completos de 1961 mencionada en la nota 1. Globalmente considerada, la creación narrativa de Francisco Espínola puede concebirse - tal como he afirmado en alguna otra ocasión-como formada por tres círculos concéntricos, cada uno de los cuales constituye un mundo narrativo con su motivación y temperatura propias, pero de tal modo comunicantes entre sí que el primero se amplía en el segundo y el segundo en el tercero, que reabsorbe en sí a los otros dos y al mismo tiempo, dialécticamente, los trasciende, del mismo modo que el segundo conserva y trasciende al primero. El conjunto, es, pues, un todo unitario, no obstante las diferencias perceptibles entre cada una de esas tres zonas de creación. Los apuntes que siguen se proponen subrayar algunos de los rasgos caracterizantes de esos tres ámbitos narrativos así como los elementos que, a pesar de sus matizaciones diversas, les confieren unidad. Pero antes de ingresar al tema que queda señalado, es preciso caracterizar la atmósfera estético-literaria den tro de la cual Francisco Espínolainició su creación narrativa. 


\section{EN LA DECADA DEL VEINTE}

2.1. En un famoso poema, titulado La muerte del cisne, el poeta mejicano Enrique González Martínez proclamóla necesidad de que los poetas le torcieran "el cuello al cisne de engañoso plumaje" y repararan en el "sapiente búho", cuya "inquieta pupila" se clava en la sombra e interpreta "el misterioso libro del silencio nocturno". Al proponer la sustitución del símbolo poético modernista, el cisne, por uno nuevo, el búho, el poeta postulaba, de hecho, la necesidad de terminar con el modernismo y emprender una creación poética que transitara por nuevas sendas. González Martínez quería que los nuevos poetas sintieran "el alma de las cosas", "la voz del paisaje" y "la vida profunda". En el Uruguay, años después, entre 1917 y 1920, Alberto Zum Felde, desde las páginas de la prensa diaria, hacía afirmaciones concordantes con la postulación poética de González Martínez:

Ha llegado la hora histórica de arrasar esa floración de papel, y matar esa fauna libresca de Sud América. Paso a la vida. Basta ya de la antigua mitología académica; basta ya de caballeros, trovadores y castillos; de los abates y las duquesas galantes de Trianón; de los pastorcillos, las aldeanas y las églogas de abanico; de las fastuosidades teatrales de las Mily una Noches, de la alcohólica bohemia del Quartier Latin, del mundanismo frivolo del boulevard; basta de musmés, gondolas, esfinges, elefantes, panoplias. Hay que quemar las marionetas literarias con que se ha estado jugando, para infundir el soplo del arte en el barro originario de la vida. Hay que dejar de mascar el papel impreso de los libros, para nutrirse con los frutos de la tierra ... Los poetas latinoamericanos son los parásitos del libro francés, las sanguijuelas de la revista de ultramar.

Y refiriéndose a los mismos poetas, concluía:

Su error es no operar con elementos propios, con la materia virgen que tienen bajo las palmas de las manos. ¿Es que la realidad del país en que viven no les ofrece elementos de arte? ¿Es que la vida natural o humana de los pueblos del Plata, no da de sí elementos estéticos? La poesía está en todas partes donde está la vida; la cuestión en saberla sentir y expresar. Y ésa es, precisamente, la facultad del artista creador. ${ }^{5}$

La superación del modernismo requerida por el poeta mejicano y el crítico uruguayo se cumple cabalmente, en el Uruguay, en la década del veinte. Los creadores - no sólo en literatura, sino también en pintura y música- se reencuentran con la tierra nativa, con el sentido y sentimiento "telúrico" de la vida, con los motivos tradicionales criollos; en el calor de la propia sangre se

\footnotetext{
${ }^{5}$ Alberto Zum Felde, Proceso intelectual del Uruguay y crttica de suliteratura. (Montevideo: Editorial Claridad, 1941), 482.
} 
busca la temperatura de la sangre del indio y del gaucho. La guitarra es el instrumento musical donde es posible hallar el mejor eco de las íntimas armonías. Se siente el valor estético del rancho, y el amor por las Arcadias modernistas es sustituido por el amor al paisaje nativo. Se buscan, en fin, raíces. Y se acepta la validez de la afirmación de Zum Felde: "con la materia virgen que tienen bajo las palmas de las manos". En música, Eduardo Fabini y Luis Cluzeau Mortet dan ya desde el título de sus composiciones el sabor de lo criollo. Fabini, con Campo (1922), La patria vieja (1925) y La isla de los ceibos (1926), y Cluzeau Mortet, con Canto del chingolo (1924) y El Pericón (1928), componen una música transida de esencias nacionales, entrañada en el paisaje uruguayo y en la tradición nativa. En pintura, Pedro Figari, que ha efectuado una lúcida inmersión en lo nativo, emerge de su buceo y crea un mundo plástico - escenas gauchas, candombes negros, paisajes del país- también transido de alma nacional, cuyas raíces las ha encontrado el pintor en un pasado que, según su propia expresión, impregna sus telas con la "luz del recuerdo". En literatura (aunque por su calidad son bien visibles escritores que siguen distinta ruta), se vive un momento de intensa concentración -como en pintura y música-sobre lonacional: Fernán Silva Valdés y Pedro Leandro Ipucheinicia respectivamente, con sus libros Agua del tiempo $(1921)^{6}$ y Alas nuevas (1922), las tendencias poéticas que ellos mismos denominan nativismo y gauchismo cósmico; Emilio Frugoni, en Poemas montevideanos (1924), busca dar en esos poemas aspectos de su Montevideo, modulando líricamente el alma de barrios, suburbios, callecitas o expresando un nostalgioso estremecimiento ante la ciudad que pierde, al crecer, su vieja fisonomia; una constelación de narradores -entre ellos, Francisco Espínola - da un conjunto de obras perdurables, en las que centran la atención en la vida rural uruguaya: Montiel Ballesteros (Alma nuestra, 1922), Justino Zavala Muniz (Crónica de Muniz, 1921, Crónica de un crimen, 1926, Crónica de la reja, 1930), Yamandú Rodríguez (Bichito de luz, 1925, Cansancio, 1927), Enrique Amorim (Tungurupá, 1926, La Carreta, 1929), Victor Dotti (Los alambradores, 1929).

"Tradicionalismo"--así surge de las consideraciones que anteceden-es el primer rasgo definitorio de los movimientos literarios, plásticos y musicales de los años veinte en el Uruguay. Paradójicamente, el segundotrazoes "Innovación". Porque la concentración sobre lo nacional y sus tradiciones no significó, por parte de los creadores - en música, plástica, literatura-un enquistamiento en viejas formas de decir o una reiteración de viejas maneras de enfrentamiento a la realidad tratada. Ocurrió todo lo contrario. Es la hora de las "literaturas

"El "nativista" Fernán Silva Valdés es, sin embargo, el autor de los dos últimos libros de filiación nútidamente modernista publicados en el Uruguay: Ánforas de barro (1913) y Humo de incienso (1917). El autor de esos libros, tal como era en los años en que los compuso, se autorretrato en un poema, "Yo era un hombre pálido", donde se describe como "un poeta pálido y marchito", "alto y decadente", que "sin saber del bien" y "sin medir el mal", "manchado de orgia" encendía sus "albas con mujeres rubias". 
europeas de vanguardia" y de la multipicación de los "ismos". Se vive una especie de "sed de novedad". Ella no fue ajena a los creadores mencionados. Cada uno de ellos se esforzó por dar del tema criollo o tradicional una visión nueva y a través de formas nuevas en su arte. El arraigo en lo tradicional no inhibió en ellos el ejercicio de la originalidad creadora. Para todos ellos son válidas algunas afirmaciones de Fernán Silva Valdés según las cuales nada hay de común entre su nativismo poético y las creaciones poéticas y narrativas de lo que él llama "el viejo criollismo". En una ocasión afirmó que:

nativismo sin renovación, sin antena receptora de los nuevos modos de sentir y de expresarse sería caer en el error de nuestro viejo criollismo que siempre le atraveso el pingo a todo lo nuevo. ${ }^{7}$

Y en otra parte asevera:

El nativismo es eso, lo repito para los sordos: un "ismo", una inquietud estética, una renovación, una novedad respecto a la vieja poesía gauchesca. ${ }^{8}$

Este afán renovador y la convicción de que estaban innovando era sentido por todos los creadores-plásticos, musicales yliterarios-que han sidomencionados. "Tradicionalismo y renovación" era la consigna de todos ellos, aún cuando esos dos términos parezcan oponerse contradictoriamente.

2.2. En 1920, año en que se preludian las tendencias narrativas, poéticas, plásticas y musicales reseñadas en el parágrafo que antecede, Francisco Espínola tenía 19 años y aún no había descubierto su verdadera vocación. Se sentía atraído por la música y proponiéndose ser concertista, tomaba clases de violín, composición y armonía. Su vocación literaria se despertó a través de su amistad con un gran escritor al que admiraba. Ese escritor era Javier de Viana (1866-1926), autor, entre otros, de tres libros fundamentales en la narrativa uruguaya: Campo (1896), cuentos, Gaucha, novela (1899), y Gurí (1901), que se integra con la novela breve que da título al libro y con varios cuentos. Todos los domingos, Espínola visitaba a Javier de Viana, que residía en un pueblo, La paz, cercano a Montevideo. En una de esas ocasiones, según contó Roberto Ibáñez en una conferencia pronunciada en octubre de 1957 en San José de Mayo, don Javier le recitó a Espínola un simple cantar:

El alma mía se muere/ay, ay, ay,/y se me muere de frío, y Espínola, ya en el tren, comenzo a bosquejar sus versos iniciales. Escribió así varios breves poemas. Y poco tiempo más tarde -era a mediados de 1922 - tras un romancillo (donde además de "cantar contaba" por primera vez) compuso un cuento, "Visita de duelo", cuya asombrosa madurez impone una evidencia no menos asombrosa:

\footnotetext{
${ }^{7}$ La Cruz del Sur 18 (Montevideo, julio-agosto de 1927).

${ }^{8}$ Fernán Silva Valdés. Autobiografía (Montevideo, Apartado de la Revista Nacional, 193 194), 34.
} 
la de que Espinola llegó a la vocación esencial de pronto y sin aprendizaje visible. A ese cuento, el más antiguo de los suyos, no tardaron en sumarse otros, de factura narrativa igualmente excepcional: de ese modo, en 1926, Espínola editó Raza ciega, libro primero, pero no primerizo: uno de los más hondos y originales de nuestras letras.

Los nueve cuentos de Raza ciega encuadran todos, estrictamente, en las coordenadas creadoras indicadas en el parágrafo 2.1. La materia narrativa de esos cuentos, proveniente de la realidad campesina uruguaya, revela la voluntad deinmersión en el "alma nacional", que es la primera de las aludidas coordenadas. De esa inmersión en el "alma nacional" —que es casi una mística comunión con ella-se emerge con un deber ineludible: el de expresarla, haciéndola verbo. Es, al respecto, bien significativa la página, titulada "La firmeza", que precede a los cuentos en la primera edición de Raza ciega (y que el autor no volvió a publicar en las siguientes). Con juvenil entusiasmo, el autor, que sólo tenía 25 años, se expresa asi:

Traed mi mejor caballo; aquél, el zaino elástico; ese que al correr parece llevar en llamas el tenso cuello. Ponedle las tibias jergas y luego la carona con punteras de cuero de jaguar y después el basto, pesado de oro y plata, donde el sol se redora y la luna se hace más blanca. Ceñidle al vientre la cincha. Cubridlo con la espuma de los cojinillos. Ahora, quitad el cabestro ${ }^{9} y$ poned en su boca el duro freno. Hoy que un libro mío comienza a llevar a otros pueblos mi pueblo, quiero cruzar, solo, los campos donde duermen los básicos de mi raza. Y de pie en los estribos, he de gritar: ¡Oh padres nuestros!, gracias porque hicisteis de mí la flor de la estirpe; gracias por converger en mí los caminos de todos los puntos del horizonte; gracias por haber hecho sensible a mi ofdo la voz de la sangre. No he olvidado un instante la misión sagrada. Noche y día tendi mi espiritu como altísima antena para recoger las vibraciones de la multitud. Noche y día vigilaba el crisol de mi conciencia. Momentos hubo en que creí con desaliento que era preciso otra vida, aún, porque lo que pensaba "no pasaba mi boca"; mas las energías oscu ras fueron cayendo por fin en él para hacerse verbo. Mucho he sufrido y ... Pero ¿qué importa a un hombre fuerte? Besad a vuestro hijo, joh sombras!

Eso he de decir. Dadme las riendas.

Adios; volveré enseguida, que es corto el tiempo y es larga la tarea.

Con la inmersión en el "alma nacional” para absorber sus esencias, vehiculizarlas en la creación narrativa, cumple Espínola con la exigencia de "tradicionalismo" impuesta por la consigna — "tradicionalismo y renovación"que impulsó la labor creadora de la mayoría de los escritores, músicos y plásticos uruguayos en el curso de la década del veinte. La exigencia de "renovación" también es visible en los cuentos de Raza ciega. El libro se ubica dentro de la

${ }^{9}$ Así en el texto. En nota al pie de página el autor expresa: "No me gusta decir cabestro". 
corriente del "criollismo" narrativo que tiene su iniciación en Charamuscas (1892) y Cuentos del pago (1893), de Benjamin Fernández y Medina, ${ }^{10}$ y que adquiere su primera expresión realmente madura y perdurable en Campo (1896), de Javier de Viana. Pues bien: si se cotejan los cuentos de Raza ciega con los de Campo, se hace bien evidente que Espínola, a pesar de su admiración por el autor de Campo y su reconocimiento de los valores propios de los cuentos de ese libro, crea un mundo imaginario totalmente dispar del instaurado por los cuentos de Javier de Viana. Dispar tanto en lo que se refiere a la visión de la realidad campesina como en los que se relaciona con la elaboración estética. El naturalismo zoleano $y$, por consiguiente, una vaga influencia del positivismo filosófico, rigen la erección del sólido edificio narrativo constituido por los once cuentos de Campo. Sin desmedro de sus auténticos valores narrativos, esos cuentos valen, en la intención del autor, como "documentos sociológicos" y tienen, incluso, sus ribetes de pretenciones científicas. (En el prólogo de su novela Gaucha, publicada tres años después de Campo, Javier de Viana expresa que ella es una "obra de verdad y hasta de ciencia"). La visión que de la realidad campesina uruguaya ofrece Javier de Viana en los cuentos de Campo es despiadadamente veraz. Ve un mundo bárbaro y primitivo y, con impasible objetividad, muestra las lacras que lo laceran. El mundo narrativo constituido por los nueve cuentos de Raza ciega, aunque es también un mundo bárbaro y primitivo, está visto desde una perspectiva opuesta a la de Javier de Viana tal como se hará ostensible más adelante-y no tiene relación alguna con el naturalismo zoleano. Raza ciega opera una radical renovación del viejocriollismo narrativo, y aunque los valores propios de éste no fueron puestos en tela de juicio, lo cierto es que - y así fue afirmado por algún crítico-los cuentos de ese inicial libro de Espínola aportaron un "estremecimiento nuevo" a la narrativa uruguaya.

${ }^{10}$ Charamuscas, volumen de cuentos que el autor subtitulo Tipos de escenas del Uruguay y Cuentos del pago, título que de por sí indica la temática de los mismos, tienen en la narrativa uruguaya verdadero carácter fundacional: inician en el Uruguay el criollismo narrativo. Muchos de los temas, situaciones, personajes y escenarios manejados posteriormente $-\mathrm{y}$ hasta hoy- por los cultores de la citada corriente narrativa fueron descubiertos, en una primera exploración, por Benajmín Fernández y Medina. Ninguno de sus cuentos es una obra maestra - todos fueron escritos antes de que el narrador cumpliera 20 años - pero si se les lee con ese cariño y lenta atención que permite descubrir las más hondas intenciones del autor, se descubre en ellos una autenticidad innegable, que proviene de una realidad asumida con amor. Hay en esos cuentos una cualidad difícilmente definible pero que "toca" fuertemente al lector. Fernández y Medina ingresó a la carrera diplomática y no escribio más narrativa, aunque, encontrándose en España, antologiz6 16 de los 30 cuentos de los libros citados y, con algunas variantes, los publicó con el título de uno de los cuentos: La flor del pago (Barcelona: Editorial Cervantes, 1923). Excluyó de la selección otra cantera temática por él descubierta: el suburbio y sus personajes, entre ellos, el compadrito. 
Raza ciega - ha escrito Alberto Zum Felde- es un libro de ambiente y caracteres gauchescos; pero la visión de ello que da en sus relatos, como cargados de electricidad dramática de alto voltaje, es distinta de todo lo que, antes y después, se ha dado en la abundante narrativa platense de ese tema y carácter. ${ }^{11}$

2.3. Los cuentos incluidos en Raza ciega son nueve: "El hombre pálido", "Pedro Iglesias", "Yerra", "María del Carmen", "Cosas de la vida", "Vista de duelo", "El angelito", "Todavia no", "Lo inefable". De estos nueve cuentos, hay uno, "Lo inefable", que difiere notablemente de los ocho restantes, en lo que se refiere a tema, ambiente y personajes y que, según manifestó el propio Espínola en alguna oportunidad, no estaba inicialmente destinado a formar parte del libro; los otros constituyen un mundo narrativo homogéneo, que por sus rasgos caracterizantes, puede ser denominado mundo primitivo de signo trágico. Excluido "Lo inefable", esos cuentos conforman el primero de los tres círculos a que se ha hecho referencia en el parágrafo 1.3.

\section{MUNDO PRIMITIVO DE SIGNO TRÁGICO}

3.1. El ambiente y caracteres de los cuentos de Raza ciega, excluido "Lo inefable", y tal como lo indica Alberto Zum Felde en la cita que cierra el parágrafo 2.2., son gauchescos. Por algunas referencias esparcidas aquí y allá a lo largo de esos cuentos, la acción de los mismos admite ser ubicada, geográficamente, en San José, departamento natal del autor y, temporalmente, en los años finales del pasado siglo e iniciales del presente. Estas precisiones no tienen, sin embargo, para la consideración crítica de Raza ciega, mayor importancia, porque su autor no procura dar en sus cuentos una versión fotográficamente naturalista de la realidad, sino crear un mundo imaginario válido y concluso en sí mismo y en el cual la materia real que le da origen, estéticamente trascendida, declare sus esencias y no sus accidentes. Esas esencias se hallan en la acción y en los personajes de los cuentos, que, más allá de su corteza regionalista, apuntan a lo permanente sustancial humano. Las rápidas pinceladas costumbristas que aparecen en los cuentos, siempre certeramente elegidas por su significación humana o por su valor estético, sólo son las estrictamente necesarias para que los personajes queden nitidamente fijados en el entorno campesino del cual son, en la intención del autor, aunque sin perder universalidad, figuras representativas.

Las afirmaciones que anteceden señalan algunos de los trazos caracterizantes de los ocho cuentos que componen el primero de los tres círculos

\footnotetext{
"En un cuento, "Yerra", la presencia de la muerte se da como una posibilidad nocumplida. Puede parecer una excepción pero no lo es.
} 
concéntricos que integran el mundo narrativo espinoliano. Esos trazos, alguno de los cuales es discernible en los otros dos ćrculos, justifican de por sí la primera nota, "mundo primitivo", de la denominación, "mundo primitivo de signo trágico", adjudicada al primero. En efecto: el medio social en que la acción de los cuentos se sitúa (esto es: la campaña uruguaya del lugar y época señalados) es un medio social que bordea la barbarie. Los seres que lo componen son seres rudamente primitivos. Exagerando un poco, es posible afirmar que más que conciencias son fuerzas de la naturaleza. En lo que se refiere al "signo trágico" que constituye el segundo término de la denominación, se justifica, en primer término, por los rasgos que singularizan el entramado anecdótico (conjunto de episodios o situaciones) y la línea argumental (acción centralizadora) de los cuentos, y, en segundo término, por la fisonomía interior de sus personajes. Tanto el entramado anecdótico como la línea argumental de los cuentos configuran situaciones intensamente dramáticas. La muerte no es ajena a ese dramatismo. Ella está presente en todos los cuentos. Incluso, uno de ellos se cierra con un homicidio y otro encuentra la génesis de su trama en un suicidio y se cierra con un asesinato. De este modo, pues, el entramado anecdótico y la línea argumental confieren una estremecedora atmósfera trágica a todos los cuentos. Hay aquí ya una primera justificación del calificativo "signo trágico". Otras se hallan en la textura del alma de los personajes. Éstos, como genuinos representantes de su medio social, son seres primitivos, elementales, exteriormente toscos y, con frecuencia, íntimamente ásperos. Pero son, también, seres conflictivos. En el fondo de sus almas batallan, en tenaz pugna, sentimientos y fuerzas vitales antagónicos. Se da, pues, en ellos, esa agonía (etimológicamente: lucha) que desgarra el ser y promueve el "sentimiento trágico de la vida" en estricto sentido unamuniano. Ese sentimiento es vivido (aunque, desde luego, sin que ellos lo sepan) por la mayoría de los personajes de los cuentos que integran el primer ćrculo del mundo imaginario espinoliano, muchos de los cuales alcanzan verdadera dimensión trágica. De este modo, la atmósfera trágica generada por el dramatismo de la acción se prolonga en la dimensión trágica de los personajes; en verdad, no puede ser de otro modo, porque aquélla y éstos son ingredientes narrativos interdependientes.

El contenido de la expresión "mundo primitivo de signo trágico" queda, con lo dicho, totalmente explicitado. Es necesario, sin embargo, subrayar otro rasgo caracterizante de los personajes de Raza ciega (incluido "Lo inefable", cuento ajeno a las disquisiciones que anteceden). Ese rasgo es el siguiente: en esos personajes tan elementales y primitivos, el autor descubre y revela vivencias de carácter moral. Y realiza una verdadera hazaña narrativa, consistente en evidenciar esas presencias éticas en los personajes sin descomponerlos ni falsearlos. La índole de esos agonistas no permite que esas vivencias morales adquieran en ellos carácter conceptual. $\mathrm{Y}$ en consecuencia, el narrador, sabiamente, hace ver (o sentir) que esas vivencias son fuerzas subliminales, impulsos profundamente "vividos" pero no "reflexivamente elaborados". Algo 
similar ocurre en los ensimismamientos - no infrecuentes- de los personajes. En esa situación, atrapan recuerdos de sucesos que de alguna manera conmovieron sus vidas e, incluso, hacen aflorar a la conciencia cosas que la memoria parecía no haber conservado; les vienen, desde el fondo del alma, vivencias afectivas, en ocasiones acariciadoramente tiernas $y$, en otras, acongojantes y perturbadoras; se hunden en ensonaaciones que operan como evasiones de la áspera realidad ... Pero su ensimismamiento no es nunca un ensimismamiento reflexivo.

3.2. Los rasgos genéricos señalados en el parágrafo anterior para los escenarios, "entramado anecdótico", "núcleo argumental" y "personajes" de los ocho cuentos que forman el primer círculo del mundo imaginario espinoliano, adquieren, sin descaracterizarse, una fisionomía bien diferenciada en cada uno de ellos, cuyo conjunto postula, en consecuencia, un mundo narrativo complejo y muy rico en variadas situaciones y personajes. Como indicio de esa riqueza, se puede subrayar que en esos ocho cuentos -ninguno de los cuales supera las dimensiones del cuento de mediana extensión- se contabilizan más de una treintena de personajes con trazos personales bien definidos. Todos esos textos, además, son un estupendo ejemplo de sabiduría narrativa en lo que se refiere a su composición. Las afirmaciones que anteceden permiten inferir sin esfuerzo que sería del mayor rendimiento crítico el análisis pormenorizado de los cuentos de que se trata. Dentrodel plan de este trabajo no cabe una tarea crítica de tanta amplitud. Pero sí es posible hacer presentir las aludidas riqueza y complejidad de ese mundo narrativo, mediante un esquemático análisis de la acción, personajes y procedimientos de composición de tres cuentos: "Pedro Iglesias", "María del Carmen" y "El angelito".

3.3. El núcleo argumental de "Pedro Iglesias" es muy sencillo: Juana, rica estanciera todavía joven y viuda de Pedro Iglesias, se casa con Ignacio, "el indio del puesto de los Talas que estaba en la Estancia desde hacía un año". Juana tiene un hijo del anterior matrimonio, Luis Maria, niño de 9 años, que mantiene vivo el recuerdo de su padre y rechaza violentamente a su padrastro. Poco a poco, además, va reaccionando contra Juana; ensimismado, piensa:

- ¡Ay, tatita! Al principio yo cré́a que el malo era él, no más. Pero ella, también. Se pasan besándose. Y ella lo busca, lo abraza. ¡Ella, tatita!

Con sus reacciones, el niño se interpone entre Juana e Ignacio. Y logra algo más: que el recuerdo del muerto se convierta para ambos en una presencia casi viva que, empujándolos, los separa. La tensión, ya insostenible, se distiende, aunque dejando a Juana dolorida y sollozante, cuando Ignacio, vencido, se aleja para siempre de Juana, de Luis María y de la Estancia. Con esta trama tan sencilla, el autor compone un cuento denso y profundo. Un sondeo penetrante y veraz en la sique de los protagonistas muestra cómo ellos viven sentimientos contradictorios: Juana, entre su amor maternal y la pasión - de fuerte contenido erótico - que la liga a Ignacio; Luis María, entre el amor a su madre 
y la repulsión que ella le inspira por su unión con Ignacio; éste, entre la atracción que le inspira Juana y la dolida conciencia de que él la separa de su hijo. Un entramado anecdótico muy rico va visualizando - con ajustadoritmo narrativola conflictualidad interior de los personajes. Pero el autor no recurre para ello al análisis sicológico. Actos y diálogos hacen evidente esa conflictualidad. Sagazmente, el autor no "dice" cuál es la situación conflictiva sino que "la hace ver". Otro procedimiento de composición característico del autor consiste en crear situaciones que valen para mostrar - en perfecta coherencia con la acción central- distintos aspectos de la realidad campesina, materia de los cuentos. "Pedro Iglesias" se abre con una espléndida escena de tal naturaleza: el almuerzo con que se celebra la boda de Juana e Ignacio. No es una mera descripción sino una escena dinámica, que inicia la acción centralizadora, crea cuatro personajes secundarios (el cura, el juez, el viejo Pascasio y la vieja Liberata), nítidamente perfilados, y vigoriza la realidad humana y estética de los personajes protagónicos.

En "Pedro Iglesias", el dramatismo de la acción se va intensificando paulatinamente a medida que se ahonda la conflictualidad interior de los personajes; en "María del Carmen", el clima trágico irrumpe desde las primeras líneas del cuento, cuando a:

los ranchos del viejo Nicanor Fernández llegó un gurí cortando campo, corriendo, y dice: - Ña Casilda, manda decir madrina que vaya enseguidita, que la finadita María del Carmen se ha matado.

La suicida, hija del viejo Rudecindo, ha tomado su trágica decisión porque Pedro -hijo del viejo Nicanor Fernández-que ha tenido amores con ella, la abandona, dejándola embarazada. Tras esta escena, se desarrolla una acción truculenta y casi increíble: el viejo Rudecindo, con consentimiento del viejo Nicanor, obliga a Pedro a que se case con el cadáver y luego, sorpresivamente, lo mata, sumiéndole la daga hasta el cabo. "-iQué ha hecho, compadre!" grita entonces el viejo Nicanor, “manotenado su puñal”. Y Rudecindo responde: “Lo que tenía que hacer! ¡Ahora, si quiere, máteme!” Nicanor, aflojando la mano que había oprimido el mango de plata, balbucea: "No hay nada que darle. Usté tenía derecho". Para hacer estéticamente válida y humanamente creíble la tramatan insólita - de "Maria del Carmen", el autor recurre a un procedimiento de composición narrativa similar al empleado en "Pedro Iglesias": crea una sucesión de situaciones en las cuales, a la vez que desenvuelve el núcleo argumental del cuento, dibuja la fisonomía interior de Rudecindo y Nicanor, haciendo "ver" y "sentir" que ambos son capaces de realizar lo que tiene lugar en la escena final, tan atroz y aparentemente inverosímil, aunque no tan inverosímil si se recuerda que la acción del cuento corresponde a la campaña uruguaya del siglo XIX, donde no faltaron personajes en cuya alma se dieron conjuntamente rasgos de grandeza y de barbarie. Con exactitud escribe Carlos Reyles: 
Los compadres Nicanor y Rudecindo, viejos de barba blanca y cuadrada, [...] son gauchos de vieja estirpe, obedientes al terrible codigo de honor y la hombría. Pertenecen a la misma línea que el Alcalde de Zalamea. Tienen la mano izquierda dadivosa y la derecha airada. Son hombres trágicos, hombres que van hasta el fin, sea el que fuere. ${ }^{12}$

Junto a estos dos personajes, hay otros (los familiares de ambos, el juez y el cura) que, por su modo de actuar, contribuyen a dar verosimilitud a la acción del cuento. Para ello, tiene especial eficacia el sagaz manejo de las reacciones del juez y del cura en la escena final, estupendamente elaborada. Cuando Rudecindo les pide que celebren el casamiento, espantados, procuran no hacerlo, pero aterrorizados ante el rebenque y el puñal de Rudecindo, realizan, entre tartamudeos y llantos, una involuntariamente absurda ceremonia, con la que logran conformar al viejo. Hay, además, en este cuento, como en toda la narrativa del autor, toques de humor certeramente distribuidos en las situaciones más intensamente dramáticas o trágicas. Son toques de un humor tierno como una caricia y que, como ha subrayado Mario Benedetti, es siempre:

frenado en el linde oportuno, cuando dar un paso más en la dirección de la burla habría significado la frustración del cuento. ${ }^{13}$

Cabe agregar que el propio Espínola se expresó así acerca de "María del Carmen":

Siempre pensé que ese cuento iba a parecer deliberadamente crudo y, en cierto modo, si no falso, por lo menos muy difícil de que ocurriera. Por eso me sorprendí́ mucho que un hombre de genio indiscutible -pero también de la peculiaridad, en todo sentido, cultural y espiritual lejos de todo realismo brutal-, que un hombre como Jules Supervielle me dijera en una carta apreciando Raza ciega, que el cuento más importante para él era "María del Carmen". ${ }^{14}$

El tema de "El angelito" está basado en una antigua costumbre de la campaña uruguaya que, cuando el cuento fue escrito, ya hacía décadas que no se practicaba. Ella consistía en celebrar una fiesta "cuando un angelito, es decir, un niño que todavía no ha actuado por sí mismo, muere ${ }^{n}{ }^{15}$ La justificación de

${ }^{12}$ Carlos Reyles, Ensayos (Montevideo: Biblioteca "Artigas"; Colección de Clásicos Uruguayos, Volumen 86, 1965). Tomo III, 281.

${ }^{13}$ Mario Benedetti, Literatura uruguaya siglo XX (Montevideo: Editorial Alfa, 1969), 86.

14 Jorge Ruffinelli, "Paco Espinola: una imagen piadosa y verdadera de los hombres". Reportaje exclusivo, Marcha 1569, Segunda Sección (12 de noviembre de 1971).

15 (Expresiones de Francisco Espínola en el reportaje referenciado en la nota 13). 
ese festejo se halla en que "en esa condición el ser no ha cometido hechos de los que condenan al Purgatorio o al Infierno, y, asi, se va derechito al Cielo" ${ }^{16}$ Con este tema, tan proclive a la mera descripción folclórica, el autor logra un cuento de excepcional jerarquía, realizado mediante una composición narrativa que él mismo llamó sinfónica. El cuento, en efecto, compone un vasto cuadro que abarca dos planos: el del patio donde tiene lugar la fiesta, dinámicamente creada mediante una multiplicidad de vívidas escenas; el de los cuartos interiores donde, en "un cajoncito de los de fideos cubierto burdamente con un paño blanco", se halla el angelito, y junto a él, su madre, cuya dolorida intimidad es evidenciada a través de varias situaciones que preparan el sorpresivo y dramático final del cuento. ${ }^{17} \mathrm{El}$ autor alterna las escenas del patio con las de los cuartos interiores, haciendo sentir así intensamente el antagonismo entre las situaciones vividas en la fiesta (beberaje, danzas, juego de prendas, amoríos y hasta conatos de pelea por motivos circunstanciales) y la dolorosa realidad que la motiva. Pero ese cuadro no es meramente descriptivo; por lo contrario: en "El Angelito" es fundamental la creación de personajes. Hay cinco personajes trabajados en profundidad: la madre, sufriente y alejada de la fiesta; el padre que casi ebrio vaga como sonámbulo entre la concurrencia; don Frutos Pareja, rico estanciero padrino del angelito y que costea la fiesta; un viejo que cándidamente adula a don Frutos para obtener buen tabaco y buena caña; la negra vieja Carola que, "con la gracia de una niña", baila con don Frutos. Junto a ellos, hay otros, más esfumados pero imprescindibles para dinamizar las escenas de la fiesta. Un análisis cabal del cuento exigiría, por su riqueza, seguirlo línea a línea. No es posible hacerlo aquí, pero sí es válido afirmar que "El angelito" es uno de los puntos cimeros de la narrativa uruguaya.

\section{MUNDO FRONTERIZO DE SIGNO EXISTENCLAL}

4.1. El segundo círculo de los tres que componen el mundo imaginario espinoliano, estáintegrado por una novela, Sombras sobre la tierra, y seis cuentos: "Lo inefable", 1926 (proveniente de Raza ciega); "El rapto", 1926, "Los cinco, 1933, “Qué lástima!", 1936, "Rancho en la noche", 1936, (reunidos en El rapto

16 (Expresiones de Francisco Espínola en el reportaje referenciado en la nota 13).

${ }^{17}$ De pronto, la fiesta se interrumpe abruptamente, porque alguien ha hecho saber que el angelito ha desaparecido. Y el cuento concluye asi:

Mudo, con los ojos saltados por la indignación, Frutos Pareja entró solo en el cuarto, pisando flores derramadas del ataúd vacio. Iba a darse vuelta para increpar a los concurrentes, cuando, al ofr algo, se acercó a la puerta de la vecina habitación. La entreabrió y se quedó helado. Sentada en la cama, plegados los labios por una sonrisa extática, los ojos en el techo, estaba la madre con el niño en brazos. No bajaba la vista como para no posarla donde no queria.

-iAh, ah, ah! ... ¡Ah, ah, ah! ... -canturreaba, meciéndolo.

$\rightarrow$ Pero comadrel -exclamó Frutos Pareja - ¿Qué hace, comadre? Lanzando un grito de pavor, la mujer se arrojó sobre el lecho y ocultó con su cuerpo el rigido cuerpito. 
$y$ otros cuentos) y "Las ratas", 1936 (recogido por primera vez en libro en la edición de Cuentos completos de 1961). ${ }^{18}$ El escenario de la acción narrativa y los personajes de este segundo círculo difieren de los del primero. Esos personajes no son los habitantes de un medio rural de vida primitiva $y$, por consiguiente, seres primitivos ellos mismos, sino seres cuya vida transcurre, en la mayoría de los casos, en los suburbios - también los bajos fondos- de una pequeña ciudad del interior del país. Son -con pocas excepcionesdesamparados sociales y todos, en mayor o menor grado, con menor o mayor lucidez, anhelan, alma adentro, un mundo en el que imperen el amor y la justicia. Experimentan, si es posible decirlo así, la nostalgia de algo no vivido pero de algún modo entrevisto en lo hondo de la propia intimidad. Estos rasgos genéricos justifican que este segundo círculo sea caracterizado como "mundo fronterizo de signo existencial". Es "fronterizo" porque los personajes socialmente son (salvo pocas excepciones, como el Juan Carlos de Sombras sobre la tierra) seres situados entre el mundo de la naturaleza, al que pertenecen los personajes del primer círculo, y el de la civilización; es de "signo existencial" porque sicológicamente los personajes viven en una especie de "intemperie existencial", hecha de la desolación y la angustia generadas por el antagonismo entre el desamparo social y el anhelo de un ensoñado mundo mejor. Cabe subrayar un detalle significativo: a diferencia de los personajes del primer círculo, los de este segundo no ignoran el mundo de los libros. En una escena de Sombras sobre la tierra, Bonifacio, que es uno de los tantos desamparados sociales de la novela, clama:

-Y hasta queremos ser buenos, queremos querer y no sabemos cómo ¿eh? ¿Quién lo explica? No ustedes que son una manga de animales, pero otros ... ¿Por qué no hablan los que son inteligentes, los que leen libros, eh? - y luego agrega -En algún libro debe de estar todo eso. Y si no está, ¿pa qué sirven los libros?

4.2. De los seis cuentos citados en el parágrafo anterior, uno "El rapto", aparece, en algunos aspectos, como marginal al mundo narrativo espinoliano. El autor enfrenta allí dos grupos de personajes: uno perteneciente a la alta burguesía y el otro, a la clase media pauperizada. Pero el interés del cuento no radica en este enfrentamiento, que es sólo un válido recurso narrativo destinado

\footnotetext{
${ }^{18}$ Los cuentos reunidos postumamente en Veladas del fog $6 n$ podrían integrar, por algunos de sus rasgos, este segundo círculo. En rigor, no encuadran estrictamente en ninguno de los tres. Cuentos de "pane lucrando" quedan un tanto al margen de la creación realmente importante del autor, aunque, desde luego, revelan el narrador nato que el mismo era. Inventiva anecd6tica, humor y amenidad son las cualidades que destacan en estos cuentos que constituyen una serie y en los que actúan siempre los mismos personajes: un gaucho viejo, don Basualdo, Doña Toribia, una negra vieja; el Mellizo Juan y su aparcero, el negro Tizón; un huérfano, Serapito, niño protegido y criado por don Basualdo.
} 
a profundizar en la sicología del personaje protagónico, Margarita, perteneciente al segundo grupo de personajes. La pequeña Margarita, niña de nueve años, "en cuya mirada había ese algo que se puede encontrar en el mirar inocente de las gacelas y en el de las mujeres muy desgraciadas y muy buenas", pero no en el de los niños, es una conciencia agónica que oscila entre la piedad que experimenta por su madre, víctima de un marido ebrio, y la desgarradora ternura que le inspira su padre, ser también desdichado, víctima, al fin, de su abulia y su alcoholismo. El drama de esta conciencia infantil se clausura con la muerte, que piadosamente, la "rapta". Este cuento, en el cual el autor bucea con lucidez y sensibilidad en una conciencia infantil, no ha sido valorado debidamente por la crítica. Peroes compartible la afirmación del autor cuando en el reportaje citado en la nota 14, expresa lo siguiente:

A pesar de que nunca se lo menciona, yo sé que no he hecho jamás un personaje tan tremendamente profundo, tan abismal como esa niña.

En otro de esos seis cuentos, "Lo inefable", el protagonista, Pedrín, humilde y candoroso servidor de un caudillo político, vive también en situación de intemperie existencial. Pero lo que no halla en la vida real, lo entrevé a través del sentimiento -inefable - que le promueve la contemplación de un cuadro, llegado a la casa de su protector el caudillo, y que representa a una hermosa joven que, abstraída, sonríe melancólicamente y de cuyos:

ojos profundos, castaños como el pelo, fluía una fuerza misteriosa que infundía a todo el rostro aire de infinito candor, de dulzura suprema, de piedad pronta a manifestarse.

La visión de esa imagen lo sume en un estado de extática adoración, que despierta en su alma "anhelos dormidos" que, a su vez, le provocan la sensación de que existen "en el mundo enternecedoras cosas desconocidas" que es posible alcanzar. En esa situación, experimenta que la Niña Bonita -así llama a la joven del cuadro - lo induce a "ser el que es", aunque no puede serlo porque se lo ha impedido su vida miserable; cree oír que ella le dice con dulzura: "Pedrín, yo estoy segura de que tú sí eres un hombre ... jeh! ... estoy segura ...”. Dramáticamente el cuento se cierra cuando Pedrín, entre un manso llorar, parece interrogar a la vida:

- ¿Por qué? ... ¿Por qué? ... ¿Por qué? ..., exclama, mientras en profundo silencio exterior, desde la iglesia vecina caen como piedras en el agua, haciendo círculos, las doce campanadas de la medianoche.

Los dos cuentos recién comentados instauran un clima intensamente dramático. En otros tres ("Rancho en la noche", "Los cinco" y "iQué lástima!") de los seis cuentos que se están comentando, ese intenso dramatismo desaparece y da 
lugar a una atmósfera narrativa en la que imperan el humor, la ternura y la gracia. Pero sus protagonistas viven también en situación de intemperie existencial y procuran evadirse de ella. Y lo hacen de distinto modo. En "Rancho en la noche" y "Los cinco" la evasión se halla en la delicia de sentirse "otros", haciendo casi real la máscara carnavalesca (porque ese sentirse otros es buscar ese otro yo más real que la vida les impide ser); en “iQué lástima!”, la evasión consiste en buscar una angélica fraternidad, tan intensa que salta las bardas de la lógica. Y así ocurre cuando Sosa, en arrebato fraterno, le ofrece su carro y su yegua tordilla a Juan Pedro. Primero le oferta: "Usté, Juan Pedro, cuando quiera la yegua, va mi casa y la saca". Pero esto es poco y hace un segundo ofrecimiento: "[...] y si yo no estoy, la saca lo mismo", pero para Sosa, tampoco ese ofrecimiento es suficiente: "Vacilo. La realidad no daba más y su ardiente pasión quería más, todavía. Y arrolló la realidad. Y salió al otro lado, terriblemente amoroso, diciendo: - - Y si la yegua no está ... justé la saca lo mismo!"

4.3. En "Las ratas", otro de los seis cuentos mencionados en 4.1., se cuenta, en primera persona, una experiencia infantil, de raíz, sin duda, autobiográfica: el horror y la piedad experimentada por el narrador, siendo muy niño, al ver quemar, con agua hirviente, a dos ratas encerradas en una trampa de alambre. “iDestrocen, ahora! ¡Traigan pestes, ahora!, enfurecidamente exclamaba la victimaria, en tanto volcaba el agua hirviente sobre los míseros animales. Más tarde, transido de piedad el niño se imagina, de noche, en "una inmensa planicie solitaria" y "con las manos desbordantes de exquisitas confituras", que reparte entre las ratas, que devoran, dice el narrador, "junto con los dulces dones, mi ternura irresistible y desbordada". Como necesita hacer real su ensoñación, venciendo su miedo, roba y compra confituras que reparte entre sus invisibles amigas, echando dentro de sus cuevas el botín del robo. El cuento (o, mejor, fragmento autobiográfico) concluye así:

Pasaron los años. Dejé el pueblo por Montevideo. Pero me ahogaba. Regresé. Y mi coraz6n me fue arrastrando hacia las míseras cuevas de quienes suelen destrozar, llevar las pestes. Ahora, éstos eran hombres. iAy, Dios mío!

De los habitantes de esas míseras cuevas extrajo Francisco Espínola materia narrativa para la elaboración de su primera novela, Sombras sobre la tierra, que integra, como se ha señalado, el segundo círculo de su creación narrativa. Toda la novela (en la que pululan esos desamparados sociales que, como tales, viven, comolos personajes de los cuentos recién analizados, en situación de "intemperie existencial") está recorrida por el mismo sentimiento piadoso experimentado por el narrador de "Las ratas" ante el martirio de aquellos dos desgraciados roedores. La piedad que el narrador siente por sus personajes impregna a la novela de un estremecido contenido evangélico que ha permitido que se relacione al autor con los grandes maestros de la narrativa rusa del siglo XIX 
(aunque debe subrayarse que el influjo de los rusos, y así lo ha subrayado Alberto Zum Felde, "si existe [...] no es directo [que, entonces, es inhibitorio], sino indirecto, es decir, operando como factor estimulante del propio temperamento del escritor"). ${ }^{19}$ Conviene señalar aquí que el sentimiento piadoso, el contenido evangélico y la solidaridad con los desamparados sociales no es rasgo exclusivo de Sombras sobre la tierra, aunque ahí llega a su climax, sino de toda la creación narrativa de Espínola, constituyéndose, por ende, en elementos unificadores de los tres círculos de que la misma se compone. Otro ingrediente unificador es la ya subrayada conjunción de componentes dramáticos y trágicos con los humorísticos. Y aquí cabe la siguiente observación, que puede parecer paradójica: el trazo humorístico con que Espínola dibuja trazos de la fisonomía de algunos de sus personajes, o con los cuales atenúa y depura estéticamente ciertas situaciones intensamente dramáticas o trágicas, es una manifestación de su solidaridad afectiva con los desamparados sociales que pueblan su mundo imaginario. Es como si enternecidamente los acariciara sonriendo, procurando al mismo tiempo acercarlos simpáticamente al alma de sus lectores, para que ellos los acojan en sí con la misma conmovida solidaridad del autor.

4.4. La crítica, casi sin excepción, al referirse a Sombras sobre la tierra ha recordado que "el tema del burdel" tiene numerosas antecedentes, tanto en la literatura europea como en la hispanoameriana. F. Ferrandiz Alborz menciona tres novelas: El burdel de Filisberto, del francés Jean Lorrain, Las siete cucas, del español Eugenio Noel y Yama, del ruso Kuprin $;{ }^{20}$ Alberto Zum Felde recuerda que varios novelistas hispanoamericanos "habían pintado antes [que Espínola], con gran maestría, en el ambiente de burdel", entre ellos, agrega, "dos chilenos ilustres, Edward Bello, en El roto, y Eduardo Barrios en Un perdido ${ }^{n} ; 1$ Emir Rodríguez Monegal afirma que "Espínola no inventa el tema, sino que lo hereda de una rica tradición europea";22 Fernando Ainsa, por fin, subraya que "la constante temática del prostíbulo y de la prostituta como heroína aparece en todos los períodos de la literatura latinoamericana". ${ }^{23}$ La exactitud de las afirmaciones críticas que anteceden es innegable. Peroesigualmente innegable que Espínola retoma "el tema del burdel" desde una óptica per sonalísima y muy honda. Sombras sobre la tierra, en la que hay, según el mismo autor, una decisiva influencia de Freud y Spengler revela muchas penetrantes y audaces intuiciones en los que se refiere a la visión que el autor tiene del alma de sus

\footnotetext{
${ }^{10}$ Loc. cit.

${ }^{20}$ "Sombras sobre la tierra". Artículo publicado en el matutino El Pats (Montevideo, 23 de enero de 1955), 3.

${ }^{21}$ Sombras...

${ }^{22}$ Sombras...

${ }^{23}$ "Una alegoria existencial: el reino sagrado de las "condenadas" sobre la tierra" (Revista de la Biblioteca Nacional 8, Montevideo, diciembre de 1974).
} 
personajes. Es, además, una novela muy rica en contenidos sociales, éticos y hasta metafísicos, y el autor maneja, asimismo, una amplia gama de recursos narrativos que la hacen, a pesar de su apariencia diáfana, estructuralmente muy compleja. En la imposibilidad de acceder aquí a un análisis en profundidad de Sombras sobre la tierra, me limitaré a exponer, a continuación, algunas de las líneas temáticas que sería necesario tener en cuenta para proceder a tal análisis.

4.5. Desde el punto de vista estructural, Sombras sobre la tierra se caracteriza por tres rasgos singularizantes: carece de una línea anecdótica centralizadora; se compone con una multitud de episodios o situaciones anecdóticamente independientes, que se explayan a través de 96 (en la $4^{\mathrm{a}}$ edición) "trozos" o capítulos sin numerar separados entre sí por asteriscos; funda su unidad novelesca mediante un núcleo de personajes cuya presencia persiste a lo largo de toda la novela y en análoga persistencia de los ambientes que configuran el escenario de la misma y que son, especialmente, los dos polos antagónicos de una pequeña ciudad del interior del país: el "bajo", donde están localizadas las mancebías y es habitáculo de los desheredados sociales, y el "centro", morada de las clases pudientes. Curiosamente, esta novela, cuyo escenario es una pequeña ciudad, adopta similar técnica estructural a la utilizada por Dos Passos en su Manhattan Transfer y Elmer Rice en La ciudad imperial, para transmitir novelescamente la vida de la gigantesca urbe norteamericana. Pero la intencionalidad creadora de Espínola, que, desde luego, no conocía las dos novelas citadas, las cuales en los años en que fue escrita Sombras sobre la tierra no habían llegado al Uruguay, difería de las de sus autores. Ellos, mediante la dispersión anecdótica procuraban hacer "sentir" el caótico ritmo de vida de la urbe gigantesca, mientras que el escritor uruguayo quería expresar, mediante la estructura dada a su novela, la inconmesurable riqueza de la vida y “[...] decir que en la vida no hay personajes importantes" ${ }^{m 4}$ (o, con una expresión castellana, que "nadie es más que nadie") y por eso en la novela, además de múltiples situaciones, hay una multitud de personajes. Mediante esa variedad de personajes y situaciones, en Sombras sobre la tierra se visualiza una extensa zona de vida y de tipos y conductas sociales, correspondientes a distintos estratos sociales.

4.6. Una categorización rigurosa de los personajes de Sombras sobre la tierra, exigiría dividirlos en varios grupos que, a su vez, se escindirían en subgrupos. Limitando los primeros y prescindiendo de los segundos, cabría

\footnotetext{
24 "Francisco Espínola, Reflexiones sobre su obra "(Montevideo: Fundación de Cultura Universitaria. Cuadernos de Literatura 4, 1968). Proporciona importante información sobre el proceso creador y personajes de Sombras sobre la tierra. Idem estos otros dos trabajos: "Francisco Espínola. Discurso en San José de Mayo" (Montevideo: Imprenta As, 1957); "Tres preguntas y sus respuestas" (Revista de la Biblioteca Nacional, citada). Son las respuestas de Espínola a las preguntas formuladas por el autor de este ensayo.
} 
establecer cuatro categorías: a) personajes del "centro" (Olga, Lala, el doctor, don Luciano, el Jefe de Policía, Román Calero, dos hermanos gordos e innominados); b) personajes del "bajo" (la Nena, Margarita, Julia, Renée, la Coca, doña Zulema e Iracema, patronas de prostíbulos, Eustaquia, Manuel Benítez, Yuca Tatú, el Mellizo Juan, los hermanos Falero, Bonifacio, Juan Gamarra, Carlín, Mangunga, el guitarrista Florisman, el Tuerto y don Sandalio, también llamado el Perro, estos dos últimos patrones de sendos cafetines situados en el "bajo"); c) personajes del "centro" pero que frecuentan el "bajo" (Juan Carlos, Martín, Pancho, el Flaco ...); ch) personajes que aparecen en una situación y luego desaparecen totalmente (algunos entre muchos: el "doliente principal" que aparece en uno de los primeros episodios, el ebrio que rememora un viejo amor y una flor azul que "intervino" en ese viejo amor, el gauchito de luto que visita por primera vez un prostibulo y que despierta una desbordante, conmovida ternura en la prostituta que lo inici) Todos estos personajes (incluidos los circunstanciales nítidamente dibujados mediantes pocos pero significativos trazos que los hacen imborrables en la memorias del lector) tienen muy rico contenido estético y humano y están profundamente definidos en su ser físico y moral. No es posible, por ende, dentro de las dimensiones de este ensayo, proceder a un análisis exhaustivo de los mismos. Sólo cabe apuntar unas esquemáticas observaciones.

4.7. En una de las tres respuestas a las tres preguntas mencionadas en la nota 24, Espínola afirma que Juan Carlos - que, dentro de ciertos límites, es un alter ego del autor- se angustia:

porque teme que toda creencia hu mana trascendente tal vez no sea otra cosa que el producto de una "sublimación" cuyos mecanismos se me habian revelado en Freud.

\section{Y luego agrega que a esa:}

angustia Juan Carlos suma la de admitir que la dirección del pensamiento individual y la impulsiva ansia inicial están en cierto modo fatalizadas por su época cultural (Spengler).

De todo lo cual, el autor concluye que "la Desolación con mayúscula que es Sombras sobre la tierra se apoya fundamentalmente, pues [...] en Spengler y en Freud". Pero es necesario subrayar que esa desolación tiene distinto signo en Juan Carlos que en los humildes habitantes del "bajo". El permanente estado de conciencia de angustia existencial vivido por Juan Carlos es, diré así, de signo negativo, porque disuelve su vida en una angustia existencial que no halla cauce seguro ni en lo humano puro ni en lo trascendente: su amor y su piedad por los desamparados sociales quedan estrangulados en sí mismos sin llegar a convertirse en fuerza creadora ( $y$ de ahí sus reincidencias en modos de la crueldad por los que luego sufre devorado por el remordimiento); por instantes entrevé una 
posible redención social de los desamparados pero nada hace por convertirla en realidad; poseído por una vaga religiosidad, se siente, no obstante, despojado de Dios (aunque en algún momento afirma que "sin la esperanza de que haya un Dios testigo de lo que no sale de nosotros, sería cosa de pegarse un balazo"). En los personajes del "bajo", hay también una angustia existencial, generada por la ignorancia y por la miseria, pero, a diferencia de Juan Carlos, que llega hasta preguntarse si la inteligencia no será "un pérfido agente de la muerte", esa angustia no promueve en esas almas inocentes una visión negativa de la vida, sino que, por lo contrario, los impulsa a ensoñar en una vida mejor y despierta en ellos la aspiración del bien. ${ }^{25}$ El cuadro de la vida de la pequeña ciudad escenario de la novela, se completa con los personajes del "centro" de rasgos antagónicos a los de Juan Carlos y a los de los personajes del "bajo". Bien dibujados, tienen vida propia, aunque su función, hasta cierto punto subsidiaria, es la de acentuar, por oposición, los trazos de la vida del "bajo" y la de Juan Carlos.

\section{MUNDO TRADICIONAL DE SIGNO POÉTICO}

5.1. El tercer círculo de los tres que componen el mundo narrativo espinoliano se integra con Saltoncito, dos cuentos, "El milagro del hermano Simplicio"(1933)y "Rodríguez" (1958) y lainconclusa novela Don Juan, el Zorro, publicada póstumamente ${ }^{26}{ }_{i}$ Cuál es el matiz que diferencia el tercer círculo del

\footnotetext{
${ }^{25}$ Así, por ejemplo, Margarita, pupila de la mancebía de Encarnación, confía en que su vida desdichada tendrá en algún momento una gran compensación.

Yodigo que Dios me reserva una felicidad muy grande-le confla a alguien. Tengo que tener una buena recompensa. Veo a otras tan felices ... Yo nunca tuve novio. Ni siquiera tuve la felicidad de que un hombre se me declarara.
}

${ }^{26}$ Don Juan, el Zorro (Montevideo: Arca Editorial, Tomo I, 229, enero de 1984; Don Juan, Tomo II, 228, junio de 1984). Los primeros fragmentos de la novela fueron publicados en 1928 por el diario Critica de Buenos Aires; los últimos dados a conocer públicamente, en 1968 , son los referenciados en la nota 4. Cuando el autor murio, en 1973, la obra quedó inconclusa. Años después, los familiares de Espínola pusieron en mis manos siete u ocho carpetas que contenían originales manuscritos y mecanografiados con incontables correcciones, mas borradores varios y apuntes de distinta naturaleza, material todo relacionado con la novela inconclusa. Un verdadero caos, cuya ordenación constituyb una tarea ardu a y apasionante, para la cual conté, en los últimos tramos, con la muy valiosa colaboración de Wilfredo Penco. Cabe preguntarse cómo en tantos años el autor no culminó su novela. En el ensayo titulado "Historia de una novela excepcional", que sirve de prólogo a Don Juan, el Zorro, expreso que Espinola puso más empeño en pensar y contar oralmente su novela que en escribirla. En realidad, las casi 500 páginas que componen la novela inconclusa, (que, segín el autor hubieran llegado a las 700 aproximadamente, al terminarla) fueron escritas en muy pocos meses, a lo largo de más de cuatro décadas. Esos pocos meses podrían ser categorizados como islas de escritura en un mar de oralidad'. 
primero y del segundo? El rasgo fundamental diferenciador se halla en que los textos que integran los dos primeros círculos, aunque no exentos de ingredientes poéticos, acentúan la perspectiva realista, mientras que los que integran el tercero, aunque sin perder contacto con la realidad, acentúan la perspectiva poética y desrealizadora. Tienen, además, en mayor o menor grado, relación con motivos populares tradicionales. Estos dos rasgos, presentes en los cuatro textos mencionados, permiten agruparlos dentro de una misma categoría creadora, pero hay entre ellos perceptibles diferencias, provenientes de la diversa manera de tratar la materia tradicional mediante distintos recursos de desrealización poetizadora.

5.2. Saltoncito es, en el Uruguay, un clásico de la literatura para niños pero, como toda literatura para niños cuando es realmente valedera, interesa también a los mayores. Aunque en distinta clave, para adaptarlos a la mentalidad infantil, los personajes muestran rasgos característicos de los otros personajes del autor de Raza ciega. Es significativo que los protagonistas de Saltoncito sean sapos. Recuérdese que el sapo es generalmente visto (una excepción: Juan Zorrilla de San Martín, que le dedica, en El sermón de la paz una deliciosa "semblanza" desbordante de simpatía y poesía) como un animal feo e incluso repulsivo. La elección de estos animales para protagonizar su novela para niños es, pues, manifestación de solidaridad con los desamparados, presente en toda la creación narrativa espinoliana. Esta novela para niños es, por lo demás, un prodigio de ternura y poesía. Idénticas calidades y cualidades son visibles en "El milagro del hermano Simplicion. El protagonista de este cuento es, como otros de los personajes del autor, un alma angélicamente inocente que, de pronto y sin pensarlo, se halla posesionado por lo inefable y busca, aunque dentro del mundo cotidiano, una vía de evasión hacia lo maravilloso. Yrealiza, según el prior del monasterio, un milagro. Un milagro tan cándidamente inocente como cándido es el mismo hermano Simplicio: paraliza la lengua del prior cuando éste, injustamente, iba a anatematizarlo. En cuanto a "Rodríguez" (que a pesar de su brevedad debe estimarse como una de las obras maestras de la narrativa uruguaya), es una estupenda y sorprendente, por lo lograda, alianza del mundo real y del mundo sobrenatural. Como en algunos cuentos populares, ambos planos se fusionan sin solución de continuidad, creando un clima poético en cuya elaboración son factores esenciales el humor y la gracia. El cuento es, además, un prodigio de síntesis o economía expresiva: pocas veces, si alguna, se habrán levantado tan enteros y se habrán integrado tal cantidad de elementos en tan pocas páginas. El impasible Rodríguez que olímpicamente desestima los más que atractivos ofrecimientos con que el Diablo procura tentarlo, avalando sus ofrecimientos con múltiples escalofriantes transformaciones, y el Diablo desesperado (y vencido) por la impasibilidad de Rodríguez, forman parte del friso de personajes inolvidables de la narrativa uruguaya.

5.3. En Don Juan, el Zorro, Francisco Espínola realiza espléndidamente el doble propósito visible en toda su creación narrativa: apresar y expresar las 
esencias del alma nacional, pero trascendiendo lo regional por la calidad estética de la realización y por la personalísima intuición vital que a través de ella se trasmite. El Don Juan, el Zorro, en efecto, arraiga en el estupendo mundo imaginario creado por el pueblo en torno a la figura del zorro, pero el autor transfigura genialmente las esencias originales de ese orbe imaginario y dialécticamentelas trasciendesin destruirlas ni desvirtuarlas. Así, por ejemplo, el zorro de la saga popular rioplatense, cuya picardía es tan grande como su astucia, se convierte, en la novela de Espínola, en paladín de los desamparados y perseguidos sociales y en representante paradigmático de los hombres libres. Su picardía se transforma en heroicidad y la novela adquiere así un soterrado contenido ético y una dimensión épica ausentes (o, todo lo más, apenas insinuados) en la creación popular. Análogas afirmaciones pueden hacerse en relación con la línea argumental, con el entramado anecdótico, con el modo de creación de personajes, con los rasgos caracterizantes de los mismos, con los recursos de composición narrativa y con el tejido verbal. En todos estos componentes, se advierte cómo el autor se ha mantenido fiel a las esencias de la saga popular pero sin dejarse apresar por los aceros del mero pintoresquismo localista. Como corroboración de estas afirmaciones valgan dos ejemplos: los personajes de la creación popular muestran incisivamente su condición animal, mientras que en la novela de Espínola son "desanimalizados" pero conservando algunos trazos que los vinculan con su origen; la entonación deliberadamente oral que impone el autor a la novela la vincula con algunos de los modos de composición narrativa popular -recuérdese, por ejemplo, a los narradores de fogón-pero la sabia estructuración de los capítulos que el autor estimó como definitivos, y los recursos narrativos de ascendencia indudablemente homérica empleados en los mismos, revelan cómo el autor supo mantenerse fiel a las esencias populares en las que estriba su narración, pero sin inhibirse para una elaboración estética de superior jerarquía. Algo más conviene agregar en relación con las afirmaciones que anteceden, porque hay otro aspecto importante que vincula la creación popular rioplatense con su transposición en clave culta realizada por Francisco Espínola. Yes la relación que ambos orbes imaginarios guardan con el realismo narrativo. Es posible afirmar que uno y otro ni lo eluden del todo ni encuadran decididamente dentro de él. El repertorio de "sucedidos" que componen la saga popular se vincula con el realismo narrativo en cuanto reflejan un ambiente y unos modos de vida bien concretos, los de la campaña uruguaya, pero se desvinculan del realismo cabal por su condición de "seres estéticos" que combinan, antirrealísticamente, rasgos animales bien acentuados y otros de carácter humano, tan acentuados como los anteriores. Una situación similar se da en el Don Juan, el Zorro de Francisco Espínola, aunque en un nivel de más alta creación estética. También en él hay un realismo narrativo básico en lo que se refiere al ambiente, a los modos de vida y a las características síquicas de los personajes, pero todo ello queda "estéticamente desrealizado" por lo que los personajes conservan - a través de sus nombres y de algunos rasgos sutil y tenuemente dibujados- de la "animalidad" en la que 
narrativamente se originan y de la que, no obstante trascenderla, no se desligan enteramente nunca. Aunque, desde luego, en el orbe imaginario creado por Espínola, los personajes alcanzan una profundidad de dimensión anterior ajena a los de la creación popular. Es válido afirmar que todos los personajes -y suman varias decenas-están dotados de una fisonomía síquica inolvidable. No está de más señalar aquí otro elemento que "estéticamente desrealiza" la creación espinoliana y es, notoriamente, su "arcaísmo". La acción, en efecto, se sitúa en los últimos años del siglo pasado y principios del presente. (En un apunte manuscrito, el autor se ubica en 189 ...). Este “arcaísmo", lo mismo que el homérico, tiene una función idealizante que lima de asperezas realistas a la narración. No debe por otra parte, olvidarse que el autor llamó siempre "poema" y no "novela" a su Don Juan, el Zorro, el cual debe considerarse como un poema épico en prosa (aunque en él no se eluden las situaciones de sesgo humorístico, las cuales, a su vez, no impiden que en muchas de sus páginas corra una veta de poderoso aliento trágico).

Las breves anotaciones que anteceden sobre Don Juan, el Zorro requieren ser completadas, siquiera sea también brevemente, con los siguientes apuntes sobre la acción narrativa y los personajes: a) Esquematizada máximamente, la línea argumental de la novela es la siguiente: El Peludo, dueño de la pulpería "La Blanqueada" y tío de la Mulita, ha propinado a ésta una soba. Para vengarla, don Juan hace que un potro arrastre al Peludo que, aunque no era tal la intención de Don Juan, como consecuencia muere. Planeando despojar a la Mulita de la pulpería, el Comisario Tigre la acusa de haberse confabulado con Don Juan para matar al Peludo. Sitiada la Mulita, junto con un joven Aperiá que la protege, ambos son muertos por las fuerzas policiales al intentar fugarse. Mientras tanto, Don Juan, que no sabe que la Mulita ha muerto y espera rescatarla, se ha refugiado con sus parciales en el monte. La novela, que como se ha dicho, quedó inconclusa, debía terminar con la descripción de una gran batalla, en la que combaten las fuerzas policiales y las de Don Juan, quien, en combate singular con el Comisario Tigre, lo mata. La línea argumental expuesta se explaya en un conjunto muy amplio de episodios o situaciones (reveladoras de una enorme inventiva) que dibujan un "panorama vital" muy vasto. El autor logra de este modo el propósito que se expresa en estas líneas:

En mi Don Juan, el Zorro, aún sin terminar, me he empeñado en ofrecer una suma de la vida típica del campo nacional de siglo pasado y principios, todavía, de éste, aspirando a hacer que al calor de la emocion estética reviva en el lector desasido de su raza aquello que físicamente murió y, sin embargo, está condicionando y condicionará por largo tiempo lo que somos (En Don Juan, el Zorro, tomo 2, Apéndice III, 226). ${ }^{27}$

${ }_{27}$ Esta doble finalidad, presente en toda la obra narrativa espinoliana es otro de los elementos - de los cuales en las páginas que anteceden se han señalado algunos -que unifican los tres círculos en que esa obra ha sido dividida. Otro elemento unificador, bien visible en los tres círculos, es la maestría del autor en lo que a composición narrativa se 
b) La facultad creadora de personajes es en Espínola excepcional y se pone de manifiesto en Don Juan, el Zorro a través de las varias decenas que en la novela (o poema) desfilan. Con gran destreza narrativa (y penetración sicológica), el autor logra crear multitud de "tipos" humanos a partir de una característica animal. Los nombres de los animales en Don Juan, el Zorro, ha escrito Guido Castillo, tienen "además de su función sustantiva, otra adjetiva, y valen como epítetos que aluden a una característica esencial del ser". ${ }^{28}$ En verdad, los personajes de Don Juan, el Zorro admiten ser analizados, desde el punto de vista sicológico, de igual modo que los agonistas de las demás obras narrativas del autor.

refiere. Tanto sus cuentos como "Saltoncito", Sombras sobre la tierra y Don Juan, el Zorro constituyen sabias lecciones de composición narrativa. Concilian calidez humana y lucidez estética. Conviene recordar que en más de una oportunidad Espínola expresó que sólo le interesaban como temas narrativos aquéllos que ofrecieran una dificultad técnica para su realización. $Y$, en verdad, supo siempre vencer esas dificultades. El análisis de los procedimientos de composición del autor de Raza ciega queda fuera del plan del presente ensayo. S6́lo cabe agregar que ellos hacen ostensible una insuperable maestría que permite que cada página de Espinola parezca de una simplicidad de agua cristalina cuando en realidad ha resuelto en ellas los más dificiles problemas de composicion narrativa.

${ }^{28}$ Guido Castillo, "Tres fragmentos de Don Juan, el Zorro" en Entregas de La Licorne 4 (Montevideo, agosto de 1954). 
